\title{
Метаболические изменения в фибробластах при взаимодействии с опухолевыми клетками: НАД(Ф)Н, ФАД, цитоплазматический рН и пероксид водорода
}

\author{
Дружкова И.Н., Лукина М.М., Дуденкова В.В., Игнатова Н.И., Ширманова М.В., Загайнова Е.В.
}

\begin{abstract}
Федеральное государственное бюджетное образовательное учреждение высшего образования «Приволжский исследовательский медицинский университет» Министерства здравоохранения Российской Федерации. 603005, Нижний Новгород, пл. Минина и Пожарского, д. 10/1
\end{abstract}

Актуальность. В последние десятилетия большое внимание уделяется исследованию роли опухолевого микроокружения в канцерогенезе и исходе лечения онкологических заболеваний. Основными клетками микроокружения являются опухоль-ассоциированные фибробласты (CAFs), которые поддерживают прогрессию опухоли. При этом между опухолевыми клетками и фибробластами формируются специфические метаболические взаимоотношения, разобщение которых рассматривается в качестве одного из современных подходов клечению опухолей.

Цель данной работы состояла в изучении метаболических изменений в фибробластах при взаимодействии с опухолевыми клетками в динамике в модели клеточного сокультивирования.

Методы. В качестве метаболических показателей исследованы иитоплазматический рН, уровень внутриклеточного пероксида водорода и эндогенные метаболические кофакторы НАД(Ф)Н И ФАД. Работа выполнена на фибробластах кожи человека и клетках рака шейки матки человека HeLa. Фибробласты культивировали совместно с опухолевыми клетками в течение 5 дней, контролем служили фибробласты в монокультуре. Метаболические кофакторы анализировали по интенсивности и времени жизни собственной флуоресценции. Цитоплазматический рН и пероксид водорода оценивали с помощью генетически-кодируемых флуоресцентных сенсоров SурНеr2 и НуPеr2, соответственно. Результаты. В условиях сокультивирования с опухолевыми клетками в фибробластах наблюдался более щелочной рН и повышенное содержание пероксида водорода по сравнению с монокультурой. Кроме того, при совместном культивировании с опухолевыми клетками в фибробластах зарегистрировано увеличение флуоресиентного редокс-отношения ФАД / НАД(Ф)Н, снижение относительных вкладов свободной формы НАД(Ф)Н и формы ФАД с открытой конформачией, что говорит о развитии окислительного метаболического статуса.

Заключение. Полученные результаты подтверждают активное метаболическое взаимодействие фибробластов с опухолевыми клетками. Динамика и степень выраженности метаболических изменений в процессе такого взаимодействия позволяют рассматривать воздействие на НАД- и ФАД-зависимые реакции энергетического обмена как перспективный способ разобщения метаболического диалога.

Ключевые слова: опухоль-ассоциированные фибробласты; опухолевое микроокружение; энергетический метаболизм; цитоплазматический $\mathrm{pH}$; пероксид водорода.

Для цитирования: Дружкова И.Н., Лукина М.М., Дуденкова В.В., Игнатова Н.И., Ширманова М.В., Загайнова Е.В. Мета-

болические изменения в фибробластах при взаимодействии с опухолевыми клетками: НАД(Ф)Н, ФАД, цитоплазматический рН и пероксид водорода. Патогенез. 2019; 17(4): 33-42

DOI: $10.25557 / 2310-0435.2019 .04 .33-42$

Для корреспонденции: Дружкова Ирина Николаевна, e-mail: danirin@yandex.ru

Финансирование: РФФИ, проект № 17-00-00193 КОМФИ

Конфликт интересов: Авторы заявляют об отсутствии конфликта интересов.

Благодарности. Авторы выражают признательность Белоусову В.В. за предоставленный материал для трансфекции, Елагину В.В. и Черкасовой Е.И. за проведение трансфекции и селекции клеток, экспрессирующих генетически кодируемые сенсоры.

Дата поступления: 19.09.2019

\section{Metabolic changes in fibroblasts during interaction with cancer cells: $N A D(P) H, F A D$, cytoplasmic $p H$, and hydrogen peroxide}

\section{Druzhkova I.N., Lukina M.M., Dudenkova V.V., Ignatova N.I., Shirmanova M.V., Zagaynova E.V.}

Privolzhsky Research Medical University, Ploshchad Minina i Pozharskogo 10/1, Nizhny Novgorod 603005, Russian Federation

Background. In the last decades, the role of microenvironment in carcinogenesis and therapeutic outcome has gained increasing attention. Cancer-associated fibroblasts (CAFs) have emerged as key players among stromal cells, which support tumor progression. In this process, a specific metabolic interplay forms between tumor cells and neighboring CAFs, and disconnection of this coupling is considered as a new therapeutic approach to anti-cancer treatment. $T$

he aim of this study was to investigate the dynamics of metabolic changes in fibroblasts during co-culturing with cancer cells. $H A D(P) H$ and FAD, the endogenous metabolic cofactors, intracellular $\mathrm{pH}$ and concentration of hydrogen peroxide were used as indexes of the metabolic status.

Methods. The study was performed on human skin fibroblasts and human cervical cancer Hela cells. Fibroblasts were cultivated in a mono- or coculture with cancer cells for 5 days. The metabolic cofactors were evaluated by intensity and lifetime of their own fluorescence. Cytoplasmic $\mathrm{pH}$ and hydrogen peroxide level were measured using genetically encoded fluorescent sensors, SypHer2 and HyPer2, respectively. 
Results. A more alkaline $\mathrm{pH}$ and increased concentration of hydrogen peroxide were observed in fibroblasts during cocultivation with cancer cells compared to the monoculture. In addition, the FAD / NAD(P)H redox-ratio was increased while relative contributions of $\mathrm{NAD}(\mathrm{P}) \mathrm{H}$ and FAD with open conformation were decreased in fibroblast during co-cultivation with cancer cells, which indicates development of the oxidative metabolic status.

Conclusion. The study confirmed the active metabolic interplay of fibroblasts with cancer cells. The dynamics and extent of the metabolic changes during this interplay suggested that affecting $N A D(P) H$-and FAD-depended reactions in the energy metabolism is a promising method for uncoupling this metabolic dialogue.

Keywords: cancer-associated fibroblasts; tumor microenvironment; energy metabolism; cytoplasmic $p H$; hydrogen peroxide.

For citation: Druzhkova I.N., Lukina M.M., Dudenkova V.V., Ignatova N.I., Shirmanova M.V., Zagaynova E.V. [Metabolic changes in fibroblasts during interaction with cancer cells: $\mathrm{NAD}(\mathrm{P}) \mathrm{H}$ and FAD, cytoplasmic $\mathrm{pH}$ and hydrogen peroxide]. Patogenez [Pathogenesis]. 2019; 17(4): 33-42 (in Russian)

DOI: $10.25557 / 2310-0435.2019 .04 .33-42$

For correspondence: Druzhkova Irina Nikolaevna, e-mail: danirin@yandex.ru

Funding: RFBR, project \#17-00-00193

Conflict of interest: The authors declare no conflict of interest.

Acknowledgments. The authors are grateful to V.V. Belousov for the provided material for transfection, V.V. Elagin and E.I. Cherkasova for transfection and selection of cells expressing genetically encoded sensors.

Received: 19.09.2019

\section{Введение}

Несмотря на возросшее понимание процессов неопластической трансформации клеток, эффективность лечения большинства типов рака по-прежнему остается низкой [1]. В поиске новых мишеней терапевтического воздействия все большее внимание исследователей занимают неопухолевые компоненты в составе злокачественных новообразований и среди них - опухоль-ассоциированные фибробласты (cancerassociated fibroblasts, CAFs) [2]. За последнее десятилетие было установлено, что CAFs являются ключевым компонентом опухолевой прогрессии [3, 4].

Уже давно за опухолью закрепилось понятие раны, которая не заживает [5]. По аналогии с раной в зоне развивающегося неопластического процесса появляются активированные фибробласты, миофибробласты, которые обладают специфическим секреторным профилем, привлекают клетки иммунной системы и стремятся «закрыть» рану, повышая пролиферативную и миграционную способность клеток [6]. В процессе ранозаживления миофибробласты элиминируются. При развитии неопластического процесса формируется специфическая популяция опухоль-ассоциированных фибробластов, которые обладают основными признаками миофибробластов и приобретают дополнительные функции, например, способность к секреции биологически активных молекул, в том числе ряда цитокинов и факторов роста $[3,7,8]$. Дальнейшее совместное развитие, или ко-эволюция, опухолевых и стромальных компонентов приводит к формированию зрелой опухоли, злокачественность, инвазивность, метастатическая активность, а также устойчивость к неблагоприятным факторам которой во многом определяется CAFs $[9,10]$. В связи с этим воздействие на CAFs и разобщение их тесного взаимодействия с раковыми клетками рассматривается в качестве новой перспективной стратегии в лечении $[2,11]$.

Недавние исследования демонстрируют высокую роль метаболической кооперации опухолевых клеток и CAFs [12]. И, если метаболические особенности самих опухолевых клеток к настоящему времени изучены достаточно хорошо, то метаболизм CAFs исследован слабо. Одни из первых работ в этой области показали наличие так называемого «обратного эффекта Варбурга» в опухоль-ассоциированных фибробластах, когда процесс анаэробного гликолиза наблюдается в основном не в опухолевых клетках, а именно в CAFs [13, 14]. Предположительно, значение данного эффекта заключается в том, что фибробласты снабжают опухолевые клетки лактатом, который используется ими в цикле трикарбоновых кислот для активации окислительного фосфорилирования $[7,15,16]$. В результате формируется метаболическая пара «гликолитический фибробласт»/«окислительная опухолевая клетка» [16, 17]. Однако каждый участник этой пары в зависимости от внешних и внутренних факторов может переключать свой метаболизм с одного типа на другой [18].

Метаболические изменения, происходящие в опухолевой ткани, тесно связаны с окислительным стрессом. Повышенный уровень активных форм кислорода (АФК) является отличительной чертой опухолей. Пероксид водорода - одна из наиболее стабильных АФК - играет ключевую роль в регуляции взаимодействия опухолевых клеток и CAFs. Пероксид водорода в большом количестве продуцируется как опухолевыми клетками без какой-либо внешней стимуляции, так и CAFs под действием фактора роста TGF- $\beta 1$, производимого опухолевыми клетками $[19,20]$. Являясь сигнальной молекулой, пероксид водорода запускает метаболические изменения, как в опухолевых клетках, так и в окружающих фибробластах [21, 22].

Целью настоящей работы было комплексное исследование метаболических изменений в нормальных фибробластах при взаимодействии с опухолевыми клетками в модели совместного культивирования in vitro. Впервые с помощью современных методов флуоресцентного биоимиджинга в живых клетках в динамике были проанализированы три параметра, имеющие отношение к метаболизму: эндогенные метаболические кофакторы восстановленный никотинамиддинуклеотид (фосфат) 
НАД(Ф)Н и окисленный флавинадениндинуклеотид ФАД, цитоплазматический $\mathrm{pH}(\mathrm{pHc})$ и уровень внутриклеточного пероксида водорода. Регистрацию НАД(Ф) Н и ФАД проводили по их собственной флуоресценции методом двухфотонной флуоресцентной микроскопии с временным разрешением (FLIM). рНс и пероксид водорода исследовали с применением оригинальных генетически-кодируемых флуоресцентных сенсоров SypHer2 и HyPer2, соответственно, для чего были получены стабильно трансфицированные клеточные линии.

\section{Материалы и методы исследования}

\section{Культуры клеток и модель сокультуры}

Исследование было проведено на опухолевых клетках линии HeLa Kyoto (рак шейки матки человека) и нормальных фибробластах кожи человека (huFB), приобретенных в ФГБУ «НИИ Вирусологии им. Д.И. Ивановского» Минздрава России. Клетки культивировали в среде ДМЕМ с 10\% содержанием бычьей сыворотки и добавлением пенициллина 100 мкг/мл и стрептомицина 100 мкг/мл при $37^{\circ} \mathrm{C}$ и влажности $80 \%$, в атмосфере с $5 \%$ содержанием $\mathrm{CO}_{2}$.

Модель сокультивирования была адаптирована из работы [23]. Для исследования взаимодействия опухолевых клеток и фибробластов получали сокультуры посевом клеток в соотношении 1: 4 (HeLa Kyoto : huFB) в количестве 20 тыс. и 80 тыс. соответственно. Регистрацию исследуемых параметров проводили по прошествии 1, 2, 3 и 5 дней после посадки клеток на чашки для флуоресцентной микроскопии FluoroDishes (день посадки принимался за день 0). Эксперименты проводили в трех повторностях, в каждой чашке исследовали 5-7 полей зрения, для количественных подсчетов брали 30-40 клеток на каждую точку наблюдения.

Для анализа рНс и пероксида водорода были получены стабильные линии фибробластов, экспрессирующие генетически-кодируемые сенсоры SypHer2 и HyPer2, соответственно. Плазмиды pLCMV-PL4-PuroHyPer2 и pLCMV-PL4-Puro-SypHer2 были любезно предоставлены проф. РАН, д.б.н. В.В. Белоусовым (ИБХ РАН). Была проведена лентивирусная инфекция по методике [24]. Для сборки вирусных частиц проводили совместную трансфекцию клеток линии НЕК 293Т тремя типами плазмид: трансферный вектор, упаковочная плазмида (p $\Delta \mathrm{R} 8.91)$ и плазмида (pMD.G), кодирующая белки вирусной оболочки. Совместную трансфекцию клеток линии НЕК 293Т проводили с использованием набора для кальций-фосфатной трансфекции (Invitrogen) по протоколу, рекомендованному производителем. Супернатант, содержащий вирусные частицы, собирали через 48 часов и 72 часа после трансфекции, фильтровали через фильтр с диаметром пор 0,45 мкм для избавления от фрагментов клеточных мембран. Затем проводили непосредственную трансдукцию фибробластов с последующей селекцией клеток со стабильной экспрессией путем добавления пуромицина в концентрации 0,5-1,0 мкг/мл. Последующий спектральный анализ популяции клеток подтвердил соответствие спектров флуоресценции полученных клеточных линий спектрам сенсоров.

Метаболический статус фибробластов по эндогенной флуоресценции кофакторов НАД(Ф)Н и ФАД исследовали на нативных немодифицированных клетках.

\section{Анализ пролиферативной активности и выживаемости клеток}

Пролиферативную активность клеток оценивали иммуноцитохимическим методом с использованием первичных антител к Ki-67 (ab15580 Abcam, США) и вторичных антител, меченых флуоресцентной меткой Alexa (ab6825, Abcam, США). Окрашивание проводили согласно протоколу производителя. Для контрастирования ядер использовали флуоресцентный краситель DAPI. Выживаемость оценивали с помощью флуоресцентного красителя пропидиума йодида согласно протоколу производителя. Исследование проведено на 5-й день культивирования в трех повторностях. Подсчет клеток производили в программе EMBL ImageJ.

\section{Исследование цитоплазматического рН (рHc) и пероксида водорода}

Флуоресцентные сенсоры SypHer2 и HyPer2 имеют два пика возбуждения на длинах волн 420 нм и 500 нм и пик эмиссии на 516 нм [25]. Исследуемые параметры оцениваются рациометрически по отношению интенсивностей флуоресценции при возбуждении на двух длинах волн $\mathrm{I}_{500} / \mathrm{I}_{420}$. С увеличением значений $\mathrm{pH}$ в случаe SypHer2 или концентрации пероксида водорода в случае HyPer2 интенсивность флуоресценции при возбуждении на длине волны 420 нм снижается, а при возбуждении на 500 нм растет.

Флуоресценцию генетически-кодируемых сенсоров регистрировали с помощью лазерного сканирующего конфокального микроскопа LSM 880 (Carl Zeiss, Германия). Изображения строились с помощью водно-иммерсионного объектива C-Apochromat $40 \times / 1.2$ NA W Korr. Для возбуждения флуоресценции на длине волны 405 нм использовали диодный лазер, для возбуждения флуоресценции на длине волны 488 нм - аргоновый лазер, регистрировали флуоресценцию в диапазоне 435-550 нм.

Рациометрический сигнал сенсоров оценивали с помощью программы EMBL ImageJ. Для этого сначала на полученных изображениях вычитали фоновый сигнал (сигнал в зоне свободной от клеток), а затем строили результирующие изображения $\mathrm{I}_{500} / \mathrm{I}_{420}$ путем деления соответствующих сигналов.

Калибровку сенсора SypHer2 в клетках проводили в буферах с высоким содержанием К+ (130 мМ глюконата калия, 20 мМ глюконата натрия, 0,5 мМ MgSO $, 0,2$ мМ ЭДТА и 30 мМ Tris (pH 8,1 - 9,0) с добавлением HEPES в присутствии ионофоров 5 мкМ нигерицина и 5 мкM монензина. Клетки инкубировали с каждым 
буфером не менее 3-4 мин для уравновешивания внеклеточного и внутриклеточного рН. Калибровочная кривая показана на рис. 1.

Корректность работы сенсора НyPer2 в трансфецированных клетках оценивали путем добавления в среду культивирования раствора пероксида водорода в концентрации 30 мкМ, что приводило к изменениям флуоресцентного сигнала в двух каналах возбуждения и результирующего отношения $\mathrm{I}_{500} / \mathrm{I}_{420}$ : интенсивность флуоресценции при возбуждении на 500 нм увеличилась с $12697 \pm 2145$ до $25261 \pm 3115$ отн.ед., для 420 нм снизилась с $9480 \pm 2203$ до $4275 \pm 1425$ отн.ед., что привело к увеличению отношения $\mathrm{I}_{500} / \mathrm{I}_{420}$ в 4,7 раза.

\section{Анализ метаболических кофакторов НАД(Ф)Н и ФАД}

Для регистрации интенсивности и времени жизни флуоресценции НАД(Ф)Н и ФАД использовали лазерный сканирующий микроскоп LSM 880 (Carl Zeiss, Германия), укомплектованный модулем для временного разрешения FLIM (Becker \& Hickl GmbH, Германия). Изображения получали с помощью водно-иммерсионного объектива C-Apochromat $40 \times / 1.2 \mathrm{NA} \mathrm{W}$ Korr. Для двухфотонного возбуждения флуоресценции использовался Ti:Sa фемтосекундный лазер Chameleon Vision II (Coherent, США) с частотой следования импульсов порядка 80 МГц и длительностью 140 фс. Флуоресценцию НАД(Ф)Н возбуждали на длине волны 750 нм, регистрировали в диапазоне 455-500 нм. Флуоресценцию ФАД возбуждали на длине волны 900 нм, принимали в диапазоне 500-550 нм. Мощность возбуждающего излучения 6 мВт. Количество фотонов в пикселе было не менее 5000, время сбора фотонов порядка 90 с. Во время эксперимента клетки находились в инкубаторе XL multi S Dark LS (PeCon GmbH, Германия) при $37^{\circ} \mathrm{C}$ и $5 \% \mathrm{CO}_{2}$. С целью увеличения точности измерения времени жизни флуоресценции и уменьшения негативного шумового вклада, эксперименты про- водились в затемненном помещении с изолированными от внешнего освещения детекторами.

Анализ полученных данных производили в программах SPCImage (Becker \& Hickl GmbH, Германия) и EMBL ImageJ. Флуоресценция кофакторов анализировалась в цитоплазме клеток. На основе интенсивности флуоресценции рассчитывали редокс-отношение ФАД / НАД(Ф)Н. Затухание флуоресценции НАД(Ф) Н и ФАД аппроксимировалось би-экспоненциальной функцией $\left(\chi^{2} \leqslant 1,20\right)$. С использованием полученных кривых затухания были рассчитаны времена жизни короткой (t1) и длинной (t2) компонент и их относительные вклады (a1, a2). В случае НАД(Ф)Н короткие времена жизни характерны для молекулы в свободной форме, которая ассоциирована с гликолизом, длинные - для связанных с белками форм, ассоциированных, в основном, с митохондриальным дыханием. В случае ФАД короткие времена жизни присущи молекуле в закрытой конформации, длинные - открытой.

\section{Статистическая обработка}

Статистический анализ был проведен с помощью программ STATISTICA 10. Были рассчитаны средние значения $(M)$ и стандартное отклонение $(S D)$. Нормальность распределения значений подтверждена с помощью критерия Шапиро-Уилка (вероятность принятия нулевой гипотезы >5\%). Сравнительный анализ данных проводили с использованием t-критерия Стьюдента (при $p \leqslant 0.05$ различия считались статистически значимыми).

\section{Результаты исследования}

\section{Пролиферативная активность и выживаемость клеток при сокультивировании}

Анализ пролиферативной активности и выживаемости опухолевых клеток и фибробластов не выявил статистически значимых отличий в условиях моно- и
A
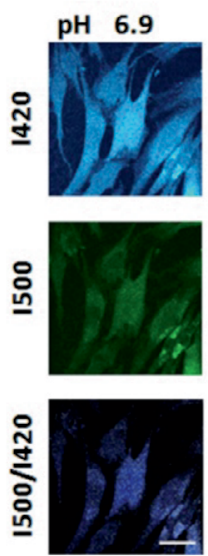

7.3
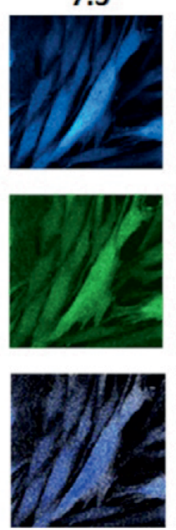
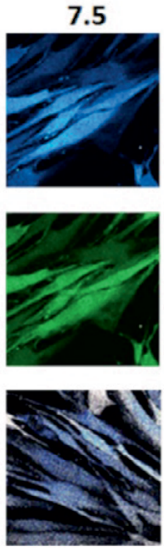
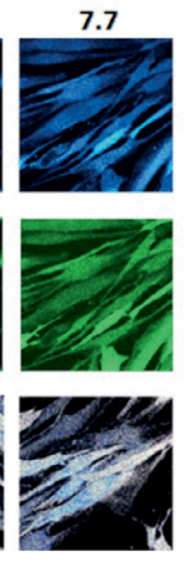
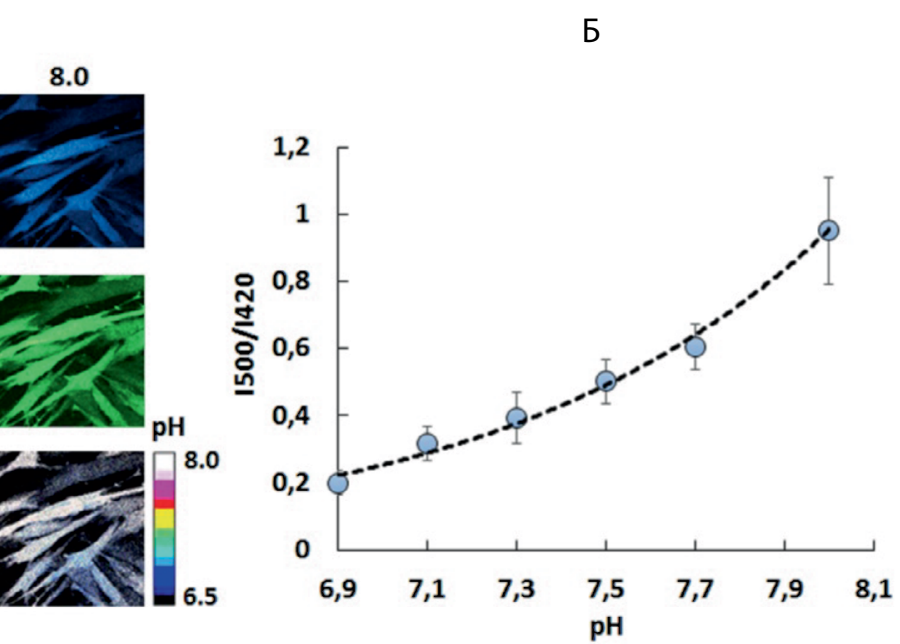

Рис. 1. Калибровка сигнала генетически-кодируемого флуоресцентного рH-сенсора SypHer2. A - серии флуоресцентных изображений фибробластов, стабильно экспрессирующих сенсор SypHer2 цитоплазматической локализации, полученные при возбуждении на двух длинах волн $\left(\mathrm{I}_{420} \mathrm{I}_{500}\right)$ и результирующие рациометрические изображения $\mathrm{I}_{500} / \mathrm{I}_{420}$ при различных значениях $\mathrm{pH}$. Масштабная линейка 50 мкм. Б - калибровочная кривая. 
сокультивирования. Среди фибробластов как в моно-, так и в сокультуре активно пролиферирующих и мертвых клеток не было выявлено (рис. 2).

\section{Цитоплазматический рН и пероксид водорода в фибробластах в монокультуре и в сокультуре с опухолевыми клетками}

Анализ цитоплазматического $\mathrm{pH}$ фибробластов с помощью генетически-кодируемого сенсора SypHer2 в динамике в течение 5 дней сокультивирования с опухолевыми клетками HeLa показал, что значения рНс постепенно снижаются с 7,47 \pm 0,09 на 1-й день до 7,14 \pm 0,10 на 5-й день в монокультуре, и с 7,58 \pm 0,09 до 7,23 \pm 0,15в сокультуре. В монокультуре фибробластов динамика изменения рНс была такая же, как и в сокультуре. При этом уровень рНс фибробластов в условиях сокультуры был сдвинут в щелочную сторону по сравнению с монокультурой фибробластов на протяжении всего периода наблюдения (рис. 3, А). Выявленное снижение рНс фибробластов в процессе культивирования может быть связано с накоплением продуктов обмена в процессе роста и размножения клеток, а также общим снижением активности клеток, вызванным контактным ингибированием.

Динамическое исследование уровня внутриклеточного пероксида водорода в фибробластах с помощью генетически-кодируемого сенсора HyPer2 показало, что в 1-й день культивирования как в монокультуре фибробластов, так и при их совместном культивиро- вании с опухолевыми клетками уровень пероксида водорода был значимо выше, чем в последующие дни, о чем свидетельствовало более высокое соотношение $\mathrm{I}_{500} / \mathrm{I}_{420}$. При этом в сокультуре уровень внутриклеточного пероксида водорода существенно превышал таковой в монокультуре (рис. 3, Б).

\section{Флуоресценция эндогенных метаболических кофакторов в фибробластах в монокультуре и в сокультуре с опухолевыми клетками}

При исследовании динамики флуоресцентного редокс-отношения ФАД / НАД(Ф)Н в условиях сокультивирования было показано, что в фибробластах данное соотношение постепенно увеличивается и достигает максимальных значений к 5-му дню (рис. 4, А). Значения редокс-отношения в монокультуре не изменялись в течение всего срока наблюдения. Стоит отметить, что в сравнении с монокультурой, фибробласты, культивируемые совместно с опухолевыми клетками, характеризовались сниженными значениями редокс-отношения вплоть до 3-го дня культивирования, и повышенными значениями на 5-й день. Полученные нами данные о более высоких значениях редокс-отношения ФАД / НАД(Ф)Н в фибробластах на позднем этапе сокультивирования свидетельствуют об их более окисленном статусе по сравнению с фибробластами в монокультуре и фибробластами на ранних сроках взаимодействия с опухолевыми клетками. В целом наблюда-
A

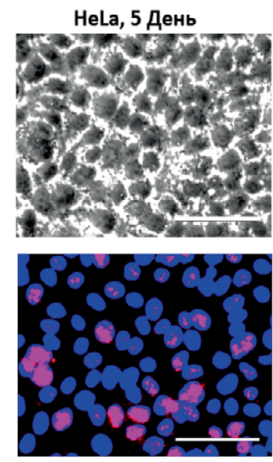

HeLa, 5 День

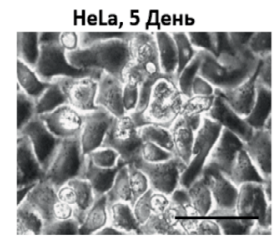

Б

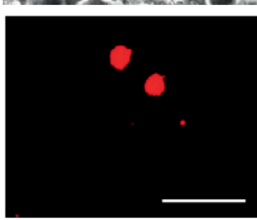

huFB, 5 День
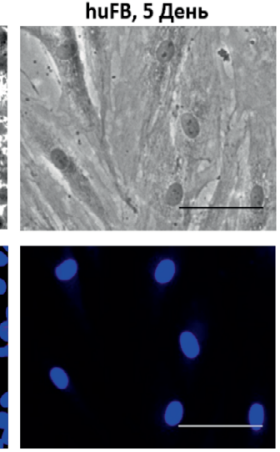

huFB, 5 День
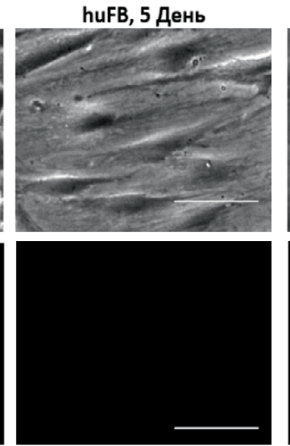

HeLa+huFB, 5 День
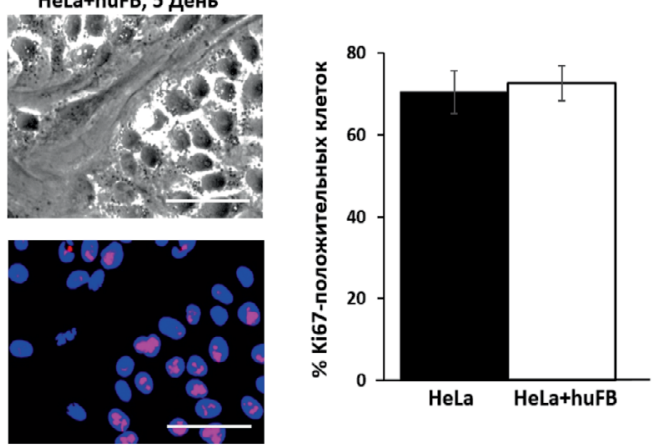

HeLa+huFB, 5 День
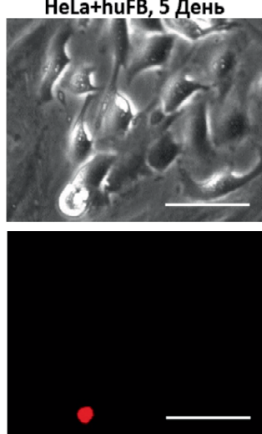

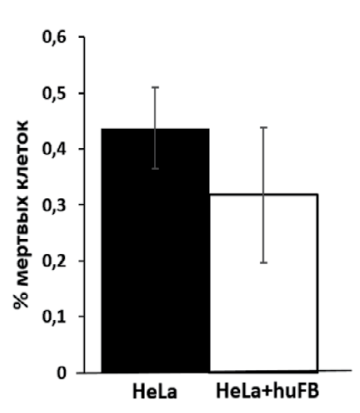

Рис. 2. Анализ пролиферативной активности (A) и выживаемости (Б) опухолевых клеток HeLa в условиях монокультивирования и сокультивирования с фибробластами. Репрезентативные микроскопические изображения опухолевых клеток и сокультуры фибробластов с опухолевыми клетками на 5-й день культивирования. Верхний ряд - изображения в проходящем свете, нижний ряд - флуоресцентные изображения DAPI (синий) и Кi67 (красный) (A); пропидиум йодид (красный) (Б). Масштабная линейка 50 мкм. M \pm SD, $n=6-10$ тыс. клеток. В сокультурах выживаемость оценивали по общему пулу клеток. 
лось значительное увеличение интенсивности флуоресценции НАД(Ф) и ФАД на 5-й день сокультивирования с опухолевыми клетками, указывающее на повышение их метаболической активности.

Анализ времен жизни флуоресценции НАД(Ф)Н и ФАД выявил характерные времена жизни кофакторов: $0,4 \pm 0,03$ нс и 2,6 $\pm 0,09$ нс у НАД(Ф)Н, 0,45 $\pm 0,04$ нс и 2,77 $\pm 0,09$ нс у ФАД без каких-либо значимых изменений в процессе культивирования. Метаболические перестройки, сопровождающие взаимодействие фибробластов с опухолевыми клетками, приводили к изменению относительных вкладов короткой и длинной компонент. Вклад короткой компоненты НАД $(Ф) Н$ al (свободная форма) фибробластов в условиях сокультивирования постепенно уменьшался, начиная с 3-го дня (рис. 4, Б). Но уже со 2-го дня его значения были статистически значимо ниже, чем в фибробластах в монокультуре. Максимальные отличия с монокультурой зарегистрированы на 5-й день (70,61 $\pm 0,98$ vs 75,44 $\pm 1,18, p<0,001)$. Одновременно с этим наблюдалось снижение вклада короткой компоненты ФАД а2 (закрытая конформация) с максимальными отличиями от монокультуры на 5-й день $(24,22 \pm 1,27$ vs 32,16 $\pm 2,29, p<0,001)$ (рис. 4, В). Обнаруженные нами относительных вкладов различных форм НАД $(Ф) Н$ и ФАД предположительно указывают на сдвиг энергетического метаболизма в сторону окислительного фосфорилирования (OXPHOS) в фибробластах в условиях сокультивирования с опухолевыми клетками.

\section{Обсуждение}

Многочисленные исследования доказывают, что, хотя генетические изменения необходимы для развития опухоли, их недостаточно для обеспечения клеток всеми злокачественными свойствами. Инфильтрация опухоли нормальными клетками хозяина является важным фактором в обеспечении благоприятных условий для опухолевой прогрессии [9, 10]. Опухолевое микроокружение включает клетки иммунной системы, ангиогенные эндотелиальные клетки, лимфатические эндотелиальные клетки, опухоль-ассоциированные фибробласты CAFs и внеклеточный матрикс [8].

Метаболизм - это фундаментальная характеристика клетки, которая определяет ее физиологические особенности. В последние годы в качестве нового подхода к противоопухолевой терапии активно исследуется возможность разобщения метаболического взаимодействия CAFs и окружающих клеток, в том числе опухолевых, а также направленное воздействие на метаболизм CAFs [2, 11]. Современные оптические методы исследования метаболизма в живых клетках, включая генетически-кодируемые сенсоры на основе флуоресцентных белков и высокочувствительные технологии время-разрешенного имиджинга, дали дополнительный толчок к его активному изучению.

В данной работе впервые было выполнено комплексное исследование нескольких метаболических показателей нормальных фибробластов - цитоплазматический рН, пероксид водорода и эндогенные кофак-
A

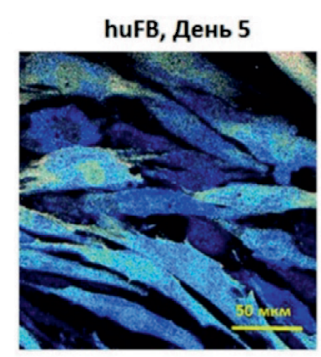

huFB+HeLa, День 5
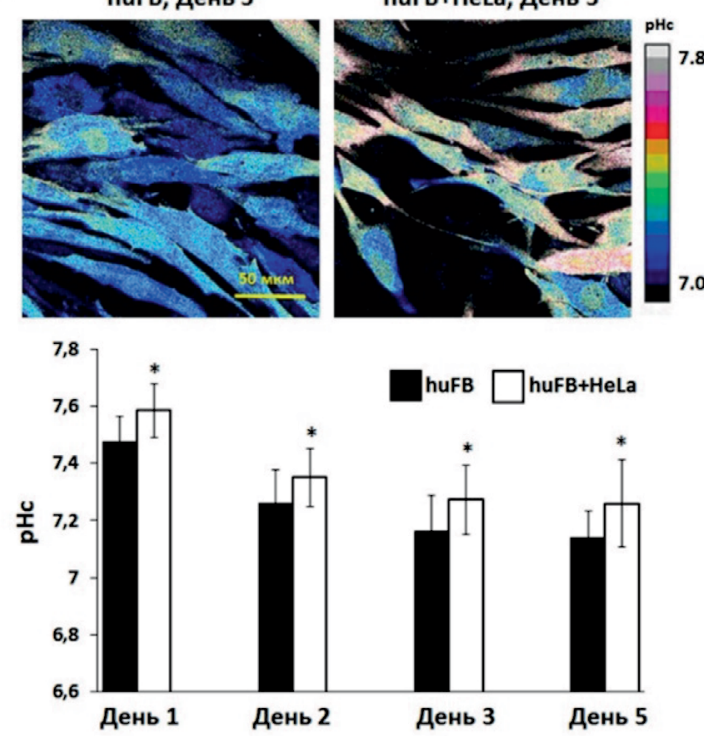

Б

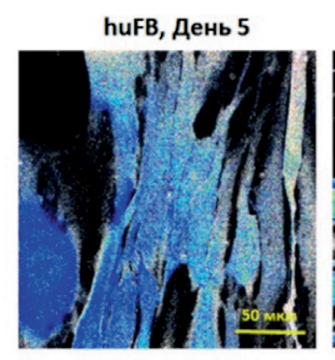

huFB+HeLa, День 5
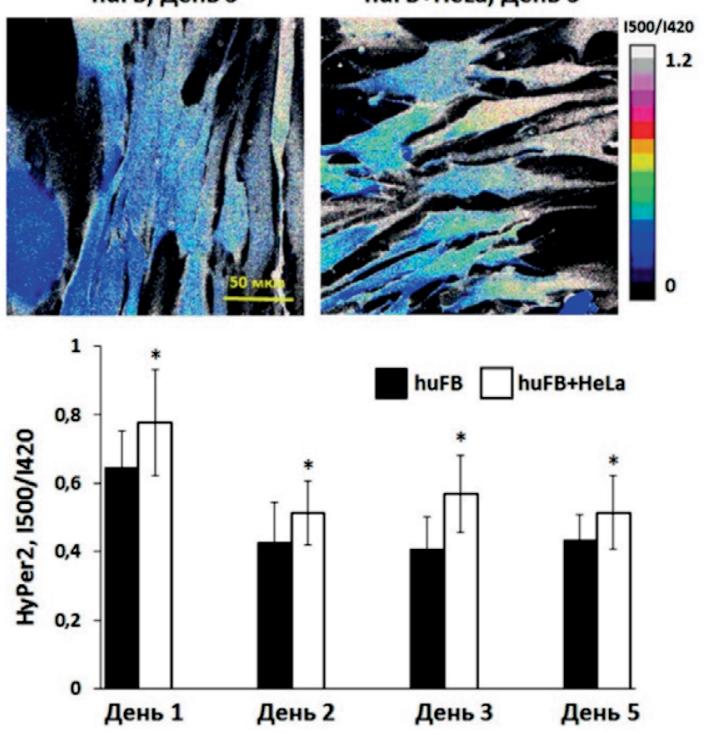

Рис. 3. Изменения цитоплазматического $\mathrm{pH}(\mathrm{A})$ и уровня пероксида водорода (Б) в фибробластах в условиях монокультивирования и сокультивирования с опухолевыми клетками HeLa. Репрезентативные микроскопические изображения фибробластов и сокультуры фибробластов с опухолевыми клетками на 5-й день культивирования. Масштабная линейка 50 мкм. Количественная оценка рНс и сигнала сенсора на пероксид водорода HyPer2. $M \pm S D, n=30-40$ клеток. * $-p \leq 0,05$ в сравнении с монокультурой. 
торы НАД(Ф)Н и ФАД - для выявления изменений, вызванных взаимодействием с опухолевыми клетками и наделяющих их функциями CAFs. Bce использованные в работе методы являются неинвазивными и позволяют вести длительные динамические наблюдения за живыми клетками в клеточной культуре и опухоли животного, как в условиях нативного роста, так и при терапии. Использование генетически-кодируемых флуоресцентных сенсоров позволило выявить защелачивание внутриклеточного пространства и повышенный уровень пероксида водорода в фибробластах, а флуоресцентная время-разрешенная микроскопия кофакторов

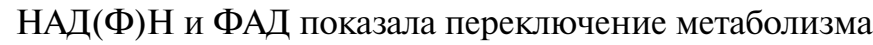
фибробластов на более окислительный тип при взаимодействии с опухолевыми клетками. Отметим, что изме- нения в $\mathrm{pH}$, уровне пероксида водорода и редокс-отношении ФАД / НАД(Ф)Н определяются рано - уже через 1 сутки совместного культивирования фибробластов с опухолевыми клетками, тогда как изменения во вкладах различных форм кофакторов, характеризующихся короткими и длинными временами жизни флуоресценции, развиваются позже - со 2-го дня и достигают наибольшей выраженности на поздних сроках наблюдения.

Более щелочной уровень цитоплазматического рН по сравнению с монокультурой наблюдался в фибробластах, взаимодействующих с опухолевыми клетками, с первого дня культивирования. В работе Үan и соавт. также было показано увеличение значений внутриклеточного $\mathrm{pH}$ в опухоль-ассоциированных и нормальных фибробластах при добавлении среды, содержащий экзосомы от опухо-
A
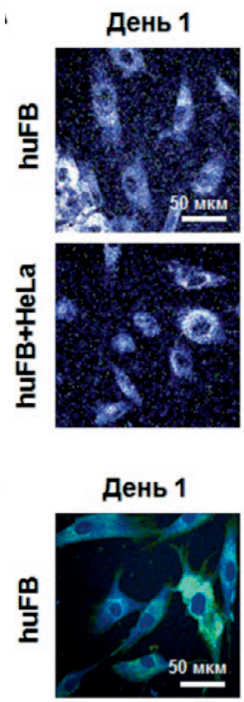

Б
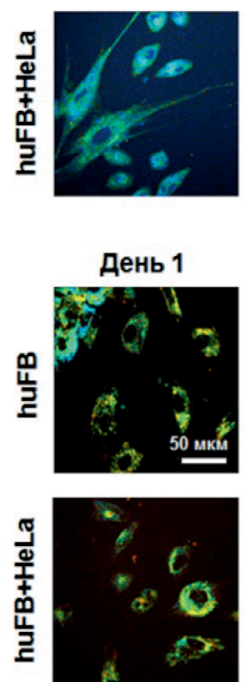

День 2

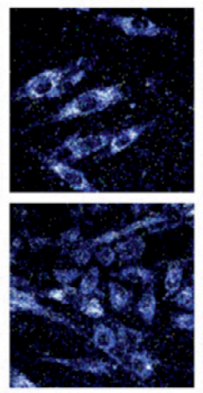

День 2
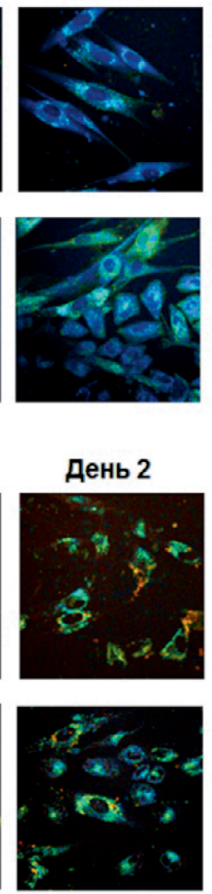

День 3

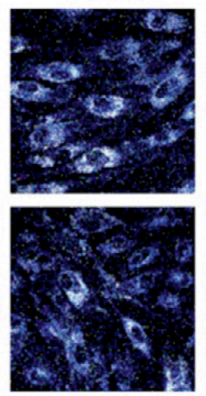

День 3
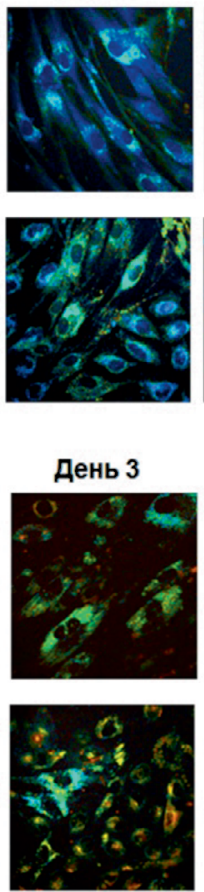

День 5
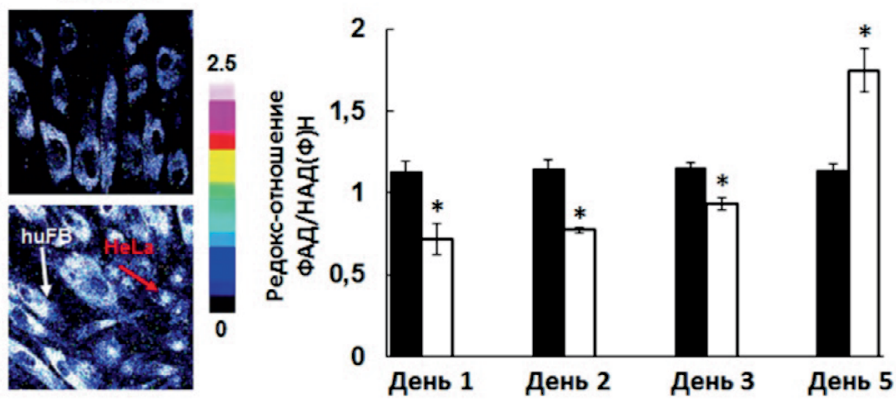

День 5
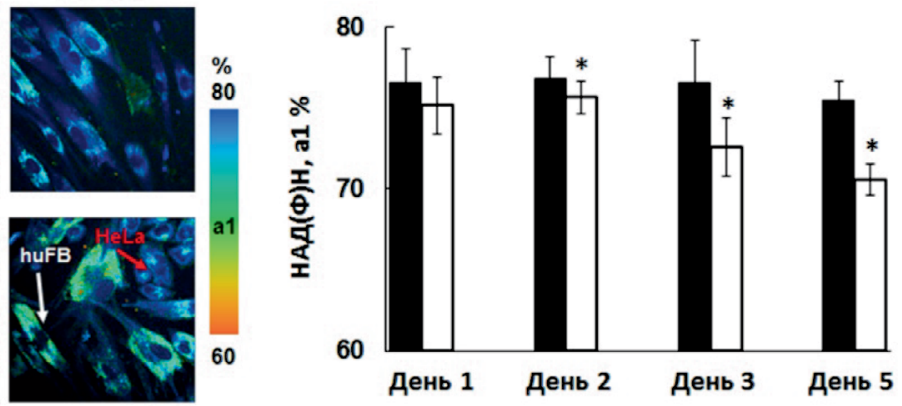

День 5
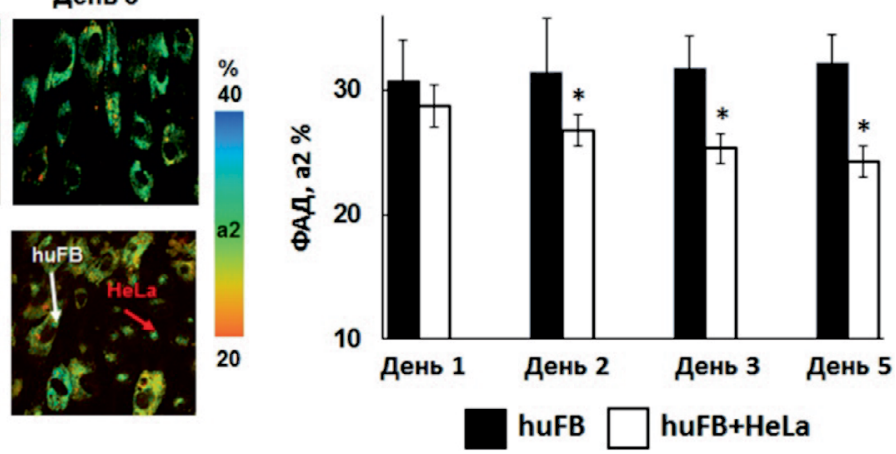

Рис. 4. Флуоресценция эндогенных метаболических кофакторов НАД(Ф)Н и ФАД в фибробластах в условиях монокультивирования и сокультивирования с опухолевыми клетками HeLa. A - флуоресцентное редокс-отношение ФАД / НАД(Ф)Н. Б - двухфотонная флуоресцентная время-разрешенная микроскопия FLIM НАД(Ф)Н, относительный вклад свободной формы НАД(Ф)Н в затухание флуоресценции (а1\%). В - двухфотонная флуоресцентная время-разрешенная микроскопия FLIM ФАД, относительный вклад открытой конформации ФАД в затухание флуоресценции (а2\%). Репрезентативные микроскопические изображения и количественная оценка соответствующих показателей. Масштабная линейка 50 мкм. $M \pm S D, n=30-40$ клеток. * $-p \leq 0,05$ в сравнении с монокультурой. 
левых клеток [26]. Кроме того, обнаруженные в этой работе более щелочные значения $\mathrm{pH}$ в фибробластах, взаимодействующих с опухолевыми клетками, сохранялись при смене внешних условий (снижение концентрации глюкозы и повышение концентрации лактата) и даже при активном транспорте лактата внутрь клеток и изменении метаболических процессов.

Кроме цитоплазматического $\mathrm{pH}$, нами было исследовано содержание внутриклеточного пероксида водорода. В качестве основных предпосылок для этого исследования послужили ранее установленное нами переключение метаболизма опухолевых клеток HeLa на гликолитический тип на второй день культивирования с фибробластами и одновременное резкое повышение содержания $\mathrm{H}_{2} \mathrm{O}_{2}$ [22]. Такие же наблюдения в отношении опухолевых клеток были сделаны в работе [23]. Кроме того, в их работе было показано двукратное увеличение содержания АФК в фибробластах на 5-й день совместного культивирования с опухолевыми клетками. Однако, судя по всему, резкое увеличение содержания АФК в фибробластах на 5-й день культивирования, описанное в работе [23], вызвано не $\mathrm{H}_{2} \mathrm{O}_{2}$. Наши данные о продукции $\mathrm{H}_{2} \mathrm{O}_{2}$ в фибробластах говорят о снижении его содержания в процессе сокультивирования с опухолевыми клетками. Максимальное содержание $\mathrm{H}_{2} \mathrm{O}_{2}$ в фибробластах наблюдалось в 1-й день роста как в моно-, так и в сокультуре, что может быть связано с высокой активностью фибробластов, вызванной адаптацией культуры, включая активный клеточный рост и синтез белков, необходимых для прикрепления к пластиковой подложке [27]. Далее уровень пероксида в монокультуре заметно снижался и оставался стабильным, как и в случае с сокультурой, однако в условиях сокультуры уровень пероксида в фибробластах был выше. В недавних исследованиях было показано, что высокое содержание $\mathrm{H}_{2} \mathrm{O}_{2}$ является нормой для CAFs [28, 29]. Как известно, фибробласты являются главным продуцентом молекул коллагена, составляющих внеклеточный матрикс [30]. Кроме того, в работах по исследованию кардиальных фиброзов и системного склероза было показано стимулирующее действие $\mathrm{H}_{2} \mathrm{O}_{2}$ на синтез коллагена фибробластами сердечной ткани и кожи [31, 32]. Поскольку синтез коллагена - это довольно универсальный процесс, а опухоль характеризуется высоким содержанием межклеточного вещества и его жёсткой структурой [33], можно предположить, что повышенный уровень $\mathrm{H}_{2} \mathrm{O}_{2}$ в фибробластах в сокультуре связан с увеличением их синтетической активности при взаимодействии с опухолевыми клетками [29].

Дополнительным методом оценки метаболического статуса в нашей работе был время-разрешенный имиджинг флуоресценции эндогенных кофакторов НАД(Ф) Н и ФАД. Кофакторы НАД и ФАД и их восстановЛенные эквиваленты НАДН и ФАДН 2 - ключевые переносчики электронов в клетке, участвующие во многих метаболических реакциях, и прежде всего, в образовании энергии в виде АТФ. НАДН образуется в процессе гли- колиза и в цикле трикарбоновых кислот. Оба кофактора работают в митохондриальной цепи переноса электронов, где НАДН окисляется до НАД, а ФАДН Фосфорилированная форма НАДН - НАДФН участвует в биосинтетических реакциях и антиоксидантной защите, обладает идентичными спектральными характеристиками с НАДН, но более длинным временем жизни флуоресценции 4.4 нс [34]. Зарегистрированные нами времена жизни НАД(Ф)Н (суммарное обозначение для НАДН и НАДФН) тиПичНЫ для НАДН, а зНачит, НАДФН не вносит существенного вклада в суммарную флуоресценцию кофермента в фибробластах. Нами был показан сушественный рост редокс-отношения ФАД / НАД(Ф)Н, снижение относительного вклада свободного НАД(Ф)Н и снижение относительного вклада ФАД в открытой конформации в фибробластах в процессе их сокультивирования с опухолевыми клетками, что указывает на сдвиг баланса метаболических процессов в сторону окислительного фосфорилирования. Подобные изменения флуоресцентных характеристик НАД(Ф)Н и ФАД могут быть вызваны как снижением уровня гликолиза, так и повышением интенсивности митохондриального дыхания. Детальная интерпретация этих результатов может быть дана только при использовании дополнительных биохимических и молекулярных методов оценки метаболизма.

Ранее в аналогичных экспериментах нами было показано переключение метаболизма клеток HeLa на более гликолитический тип при культивировании с фибробластами [22]. Следовательно, взаимодействие фибробластов с опухолевыми клетками данного типа, показанное в данной работе, соответствует классическому типу энергетического метаболизма опухоли - эффекту Варбурга. Деление опухолей на типы в зависимости от метаболических взаимодействий между опухолевыми клетками и стромой было предложено в исследовании Liu и соавт, проведенном на раке молочной железы. Были выделены четыре типа опухолей: эффект Варбурга (гликолиз в опухолевых клетках / OXPHOS в фибробластах), обратный эффект Варбурга (OXPHOS в опухолевых клетках / гликолиз в фибробластах), смешанный тип (гликолиз в обоих типах клеток) и нулевой тип (OXPHOS в обоих типах клеток) [35]. Однако, стоит отметить, что как опухолевым клеткам, так и CAFs свойственна метаболическая пластичность в зависимости от условий окружающей среды $[32,36]$.

Формирование взаимодействий фибробластов с опухолевыми клетками по типу эффекта Варбурга и генерация $\mathrm{H}_{2} \mathrm{O}_{2}$ опухолевыми клетками на начальном этапе их взаимодействия согласуются с предположением о том, что гликолитический тип метаболизма стимулируется в опухолевых клетках из-за нарушения метаболизма кислорода в результате которого вместо окислительного фосфорилирования с образованием АТФ идет процесс образования $\mathrm{O}_{2}$ и $\mathrm{H}_{2} \mathrm{O}_{2}$. В свою очередь $\mathrm{H}_{2} \mathrm{O}_{2}$ может активировать в фибробластах цикл трикарбоновых кислот, который является универсальным антиоксидантным 
механизмом, в котором основная роль принадлежит a-кетоглуторату [37]. При этом лактат, поступающий из опухолевых клеток, может служить субстратом для цикла трикарбоновых кислот. Поскольку переход лактата в пируват сопровождается восстановлением НАД ${ }^{+}$до НАДН, это может вести к росту флуоресцентного сигнала НАД(Ф)Н, который мы и наблюдаем в фибробластах.

\section{Заключение}

Таким образом, выполненное нами исследование метаболизма фибробластов подтверждает высокую роль метаболического «симбиоза» в формировании опухоль-стромальных взаимодействий и влиянии опухолевых клеток на метаболизм фибробластов. Полученные данные о цитоплазматическом $\mathrm{pH}$, внутриклеточном пероксиде водорода и флуоресцентных кофакторах НАД(Ф)Н и ФАД - участниках клеточной биоэнергетики, свидетельствуют о том, что наиболее выраженные изменения, обусловленные взаимодействием с опухолевыми клетками, характерны для НАД(Ф)Н- и ФАД-зависимых биохимических процессов, тогда как вариации рН и пероксида водорода в большей степени связаны с условиями культивирования фибробластов, и в меньшей степени - с их взаимодействием с опухолевыми клетками. Исходя из этого, модификация энергетического метаболизма фибробластов, например, путем ингибирования OXPHOS и возвращения к гликолитическому фенотипу, может рассматриваться как потенциальный подход для разобщения их взаимодействия с клетками рака шейки матки с целью угнетения роста опухоли. Известны фармакологические ингибиторы комплексов дыхательной цепи митохондрий и разобщители OXPHOS, применяемые в клинике для лечения различных неонкологических заболеваний, а также ряд новых субстанций [38, 39]. В последнее время проводится много исследований, как экспериментальных, так и клинических, по оценке их противоопухолевой активности. Принимая во внимание высокий базовый уровень OXPHOS в клетках рака шейки матки [40], можно ожидать, что неспецифическое ингибирование окислительного метаболизма одновременно в опухолевых клетках и фибробластах окажет сильный противоопухолевый эффект. Изучение возможности модификации метаболизма CAFs ингибиторами OXPHOS станет предметом наших дальнейших исследований.

\section{Список литературы/References}

1. Zugazagoitia J., Guedes C., Ponce S., Ferrer I., Molina-Pinelo S., Paz-Ares L. Current Challenges in Cancer Treatment. Clin. Ther. 2016; 38(7): 1551-1566. DOI: 10.1016/j.clinthera.2016.03.026

2. Valkenburg K.C., de Groot A.E., Pienta K.C. Targeting the tumour stroma to improve cancer therapy. Nat. Rev. Clin. Oncol. 2018; 15(6): 366-381. DOI: 10.1038/s41571-018-0007-1

3. Marsh T., Pietras K., McAllister S.S. Fibroblasts as architects of cancer pathogenesis. Biochim. Biophys. Acta. 2013; 1832(7): 10701078. DOI: $10.1016 /$ j.bbadis.2012.10.013

4. Fiori M.E., Di Franco S., Villanova L., Bianca P., Stassi G. De Maria R. Cancer-associated fibroblasts as abettors of tumor progression at the crossroads of EMT and therapy resistance. Molecular Cancer. 2019; 18(1): 70. DOI: 10.1186/s12943-019-0994-2

5. Dvorak H.F. Tumors: wounds that do not heal. Similarities between tumor stroma generation and wound healing. N. Engl. J. Med. 1986; 315(26): 1650-1659. DOI: 10.1056/NEJM198612253152606

6. Nurden A.T. Platelets, inflammation and tissue regeneration. Thromb. Haemost. 2011; 105(Suppl. 1): S13-S33. DOI: 10.1160/ THS10-11-0720

7. Öhlund D., Elyada E., Tuveson D. Fibroblast heterogeneity in the cancer wound. J. Exp. Med. 2014; 211(8): 1503-1523. DOI: 10.1084/ jem.20140692

8. Kalluri R. The biology and function of fibroblasts in cancer. Nat. Rev. Cancer. 2016; 16(9): 582-598. DOI: 10.1038/nrc.2016.73

9. Hanahan D., Weinberg R.A. Hallmarks of cancer: the next generation Cell. 2011; 144(5): 646-674. DOI: 10.1016/j.cell.2011.02.013

10. Massague J, Obenauf A.C. Metastatic colonization by circulating tumour cells. Nature. 2016; 529(7586): 298-306. DOI: 10.1038/ nature 17038

11. Prakash J. Cancer-Associated Fibroblasts: Perspectives in Cancer Therapy. Trends Cancer. 2016; 2(6): 277-279. DOI: 10.1016/j. trecan.2016.04.005

12. Lopes-Coelho F., Gouveia-Fernandes S., Serpa J. Metabolic cooperation between cancer and non-cancerous stromal cells is pivotal in cancer progression. Tumour Biol. 2018; 40(2): 1010428318756203. doi: $10.1177 / 1010428318756203$

13. Chaudhri V.K, Salzler G.G, Dick S.A., Buckman M.S., Sordella R., Karoly E.D., Mohney R., Stiles B.M., Elemento O., Altorki N.K., McGraw T.E. Metabolic alterations in lung cancer-associated fibroblasts correlated with increased glycolytic metabolism of the tumor. Mol. Cancer Res. 2013; 11(6): 579-592. 10.1158/1541-7786. MCR-12-0437-T

14. Rattigan Y.I., Patel B.B., Ackerstaff E., Sukenick G., Koutcher J.A., Glod J.W., Banerjee D. Lactate is a mediator of metabolic cooperation between stromal carcinoma associated fibroblasts and glycolytic tumor cells in the tumor microenvironment. Exp. Cell Res. 2012; 318(4): 326-335. DOI: 10.1016/j.yexcr.2011.11.014

15. Zhao H., Yang L., Baddour J., Achreja A., Bernard V., Moss T., Marini J.C., Tudawe T., Seviour E.G., San Lucas F.A., Alvarez H., Gupta S., Maiti S.N., Cooper L., Peehl D., Ram P.T., Maitra A., Nagrath D. Tumor microenvironment derived exosomes pleiotropically modulate cancer cell metabolism. eLife. 2016; 5: e10250. DOI: $10.7554 /$ eLife. 10250

16. Martinez-Outschoorn U.E., Sotgia F., Lisanti M.P. Caveolae and signalling in cancer. Nat. Rev. Cancer. 2015; 15(4): 225-237. DOI: $10.1038 / \mathrm{nrc} 3915$

17. Shiga K., Hara M., Nagasaki T., Sato T., Takahashi H., Takeyama $\mathrm{H}$. Cancer-associated fibroblasts: their characteristics and their roles in tumor growth. Cancers. 2015; 7(4): 2443-2458. DOI: 10.3390/ cancers7040902

18. Gentric G., Mieulet V., Mechta-Grigoriou F. Heterogeneity in cancer metabolism: new concepts in an old field. Antioxid. Redox Signal. 2017; 26(9): 462-485. DOI: 10.1089/ars.2016.6750

19. Costa A., Scholer-Dahirel A., Mechta-Grigoriou F. The role of reactive oxygen species and metabolism on cancer cells and their microenvironment. Semin. Cancer Biol. 2014; 25: 23-32. DOI: 10.1016/j.semcancer.2013.12.007

20. Toullec A., Gerald D., Despouy G., Bourachot B., Cardon M., Lefort S., Richardson M., Rigaill G., Parrini M.C., Lucchesi C., Bellanger D., Stern M.H., Dubois T., Sastre-Garau X., Delattre O., Vincent-Salomon A., Mechta-Grigoriou F. Oxidative stress promotes myofibroblast differentiation and tumour spreading. EMBO Mol. Med. 2010; 2(6): 211-230. DOI: 10.1002/emmm. 201000073

21. Lisanti M.P, Martinez-Outschoorn U.E, Lin Z., Pavlides S., Whitaker-Menezes D., Pestell R.G., Howell A., Sotgia F. Hydrogen peroxide fuelsaging, inflammation, cancer metabolism and metastasis. Cell Cycle. 2011; 10(15): 2440-2449. DOI: 10.4161/cc.10.15.16870

22. Druzhkova I.N., Shirmanova M.V., Lukina M.M., Dudenkova V.V., Mishina N.M., Zagaynova E.V. The metabolic interaction of cancer cells and fibroblasts - coupling between NAD (P)H and FAD, intracellular $\mathrm{pH}$ and hydrogen peroxide. Cell Cycle. 2016; 15(9): 12571266. DOI: $10.1080 / 15384101.2016 .1160974$

23. Martinez-Outschoorn U.E., Lin Z., Trimmer C., Flomenberg N., Wang S., Pavlides S., Pestell R.G., Howell A., Sotgia F., Lisanti M.P. Cancer cells metabolically "fertilize" the tumor microenvironment 
with hydrogen peroxide, driving the Warburg effect. Implications for PET Imaging Hum Tumors. Cell Cycle. 2011; 10(15): 2504-2520. DOI: $10.4161 /$ cc.10.15.16585

24. Zufferey R., Nagy D., Mandel R.J., Naldini L., Trono D. Multiply attenuated lentiviral vector achieves efficient gene delivery in vivo. Nat. Biotechnol., 1997, 15(9), 871-887. DOI: 10.1038/nbt0997-871

25. Matlashov M.E., Bogdanova Y.A., Ermakova G.V., Mishina N.M., Ermakova Y.G., Nikitin E.S., Balaban P.M., Okabe S., Lukyanov S.A., Enikolopov G., Zaraisky A.G, Belousov V.V., Fluorescent ratiometric $\mathrm{pH}$ indicator SypHer2: applications in neuroscience and regenerative biology. Biochim. Biophys. Acta. 2015; 1850(11): 2159-2392. DOI: $10.1016 /$ j.bbagen.2015.08.002

26. Yan W., Wu X., Zhou W., Fong M.Y., Cao M., Liu J., Liu X., Chen C.-H., Fadare O., Pizzo D.P., Wu J., Liu L., Liu X., Chin A.R., Ren X., Chen Y., Locasale J.W., Wang S.E. Cancer-cell-secreted exosomal miR-105 promotes tumour growth through the MYC-dependent metabolic reprogramming of stromal cells. Nat. Cell Biol. 2018; 20(5): 597-609. DOI: 10.1038/s41556-018-0083-6

27. Zhang Q., Liu C., Hong S., Min J., Yang Q., Hu M., Zhao Y., Hong L. Excess mechanical stress and hydrogen peroxide remodel extracellular matrix of cultured human uterosacral ligament fibroblasts by disturbing the balance of MMPs/TIMPs via the regulation of TGF- $\beta 1$ signaling pathway. Mol. Med. Rep. 2017; 15(1): 423-430. DOI: $10.3892 / \mathrm{mmr} .2016 .5994$

28. Arcucci A., Ruocco M.R., Granato G., Sacco A.M., Montagnani S. Cancer: An Oxidative Crosstalk between Solid Tumor Cells and Cancer Associated Fibroblasts. BioMed. Res. Int. 2016; 2016:4502846. DOI: $10.1155 / 2016 / 4502846$

29. Liao Z., Tan Z.W., Zhu P., Tan N.S. Cancer-associated fibroblasts in tumor microenvironment -Accomplices in tumor malignancy. Cell. Immunol. 2018; 343: 103729. DOI: 10.1016/j.cellimm.2017.12.003

30. McAnulty R.J. Fibroblasts and myofibroblasts: their source, function and role in disease. Int. J. Biochem. Cell. Biol. 2007; 39(4): 666-671. DOI: 10.1016/j.biocel.2006.11.005

31. Servettaz A., Guilpain P., Goulvestre C., Chéreau C., Hercend C., Nicco C., Guillevin L., Weill B., Mouthon L., Batteux F. Radical oxygen speciesproduction induced by advanced oxidation protein products predicts clinical evolution and response to treatment in systemic sclerosis. Ann. Rheum. Dis. 2007; 66(9): 1202-1209. DOI: 10.1136/ ard.2006.067504

32. Wang P., Zhou S., Xu L., Lu Y., Yuan X., Zhang H., Li R., Fang J., Liu P. Hydrogen peroxide-mediated oxidative stress and collagen synthesis in cardiac fibroblasts: Blockade by tanshinone IIA. J. Ethnopharmacol. 2013; 145(1): 152-161. DOI: 10.1016/j. jep.2012.10.044

33. Ng M.R., Brugge J.S. A stiff blow from the stroma: collagen crosslinking drives tumor progression. Cancer Cell. 2009; 16(6): 455-457. DOI: $10.1016 /$ j.ccr.2009.11.013

34. Blacker T.S., Mann Z.F., Gale J.E., Ziegler M., Bain A.J., Szabadkai G., Duchen M.R. Separating NADH and NADPH fluorescence in live cells and tissues using FLIM. Nat. Commun. 2014; 5: 3936. DOI: $10.1038 /$ ncomms4936

35. Liu J., Mid J., Zhou B.P. Metabolic rewiring in cancer-associated fibroblasts provides a niche for oncogenesis and metastatic dissemination. Mol. Cell. Oncol. 2016; 3(1): e1056331. DOI: 10.1080/23723556.2015.1056331

36. Wanandi S.I., Ningsih S.S., Asikin H., Hosea R., Neolaka G.M.G. Metabolic Interplay between Tumour Cells and Cancer-Associated Fibroblasts (CAFs) under Hypoxia versus Normoxia. Malays. J. Med. Sci. 2018; 25(3): 7-16. DOI: 10.21315/mjms2018.25.3.2

37. Mailloux R.J., Bériault R., Lemire J., Singh R., Chénier D.R., Hamel R.D., Appanna V.D. The tricarboxylic acid cycle, an ancient metabolic network with a novel twist. PlosOne. 2007; 2(8): e690. DOI: $10.1371 /$ journal.pone.0000690

38. Ashton T.M., McKenna W.G., Kunz-Schughart L.A., Higgins G.S. Oxidative Phosphorylation as an Emerging Target in Cancer Therapy. Clin. Cancer Res. 2018; 24(11): 2482-2490. DOI: 10.1158/1078-0432. CCR-17-3070

39. Shahruzaman S.H., Fakurazi S., Maniam S. Targeting energy metabolism to eliminate cancer cells. Cancer Manag. Res. 2018; 10: $2325-$ 2335. DOI: 10.2147/CMAR.S167424

40. Rodríguez-Enríquez S., Vital-González P.A., Flores-Rodríguez F.L., Marín-Hernández A., Ruiz-Azuara L., Moreno-Sánchez R. Control of cellular proliferation by modulation of oxidative phosphorylation in human and rodent fast-growing tumor cells. Toxicol. Appl. Pharmacol. 2006; 215(2), 208-217. DOI: 10.1016/j.taap.2006.02.005

\section{Сведения об авторах:}

Дружкова Ирина Николаевна - младший научный сотрудник лаборатории индивидуальной химиотерапии рака Федерального государственного бюджетного образовательного учреждения высшего образования «Приволжский исследовательский медицинский университет» Министерства здравоохранения Российской Федерации; https://orcid.org/0000-0003-0293-3069

Лукина Мария Максимовна - младший научный сотрудник лаборатории индивидуальной химиотерапии рака Федерального государственного бюджетного образовательного учреждения высшего образования «Приволжский исследовательский медицинский университет» Министерства здравоохранения Российской Федерации; https://orcid.org/0000-0003-1374-8571

Дуденкова Варвара Вадимовна - кандидат физико-математических наук, младший научный сотрудник лаборатории высокоразрешающей микроскопии и генных технологий Федерального государственного бюджетного образовательного учреждения высшего образования «Приволжский исследовательский медицинский университет» Министерства здравоохранения Российской Федерации; https://orcid.org/0000-0001-6761-5585

Игнатова Надежда Ивановна - кандидат биологических наук, доцент кафедры эпидемиологии, микробиологии и доказательной медицины Федерального государственного бюджетного образовательного учреждения высшего образования «Приволжский исследовательский медицинский университет» Министерства здравоохранения Российской Федерации; https://orcid.org/0000-0002-4570-9342

Ширманова Марина Вадимовна - кандидат биологических наук, заместитель директора по науке, заведующая научной лабораторией индивидуальной химиотерапии рака научно-исследовательского института экспериментальной онкологии и биомедицинских технологий Федерального государственного бюджетного образовательного учреждения высшего образования «Приволжский исследовательский медицинский университет» Министерства здравоохранения Российской Федерации; https://orcid.org/0000-0002-3207-7227

Загайнова Елена Вадимовна - доктор медицинских наук, профессор РАН, директор научно-исследовательского института экспериментальной онкологии и биомедицинских технологий Федерального государственного бюджетного образовательного учреждения высшего образования «Приволжский исследовательский медицинский университет» Министерства здравоохранения Российской Федерации; https://orcid. org/0000-0003-2097-0525 